Molecular

Syndromology
Editorial - Late Breaking Chromosomes

Mol Syndromol 2020;11:178-182

DOI: $10.1159 / 000510878$

\title{
Fanconi Anemia: A Syndrome of Anemia and Skeletal Malformations Progressing to a Gene Network Involved in Genomic Stability and Malignant Disease
}

In 1927, the Swiss pediatrician Guido Fanconi reported on three siblings with aplastic anemia and skeletal malformations (hypoplasia of the thumbs and radial hypoplasia) [Fanconi, 1927]. Initially, the hematologic disorder was described as "panmyelopathy," and multiple genes were thought to cause the complexity of the symptoms in these children. Thus, possible polygenic causation would interfere with efforts to isolate "the gene" for Fanconi Anemia (FA). After several efforts had failed, not polygenic inheritance, but locus heterogeneity was considered. The latter was resolved by in vitro functional complementation assays. With this approach, the first FA gene, FANCC, was isolated [Strahdee et al., 1992]. In this way, an additional four FANC genes were subsequently isolated [Lo Ten Foe et al., 1996; de Winter et al., 1998; 2000a; 2000b]. Meanwhile, 22 FANC genes, spanning the alphabet from $\mathrm{A}$ to $\mathrm{W}$, have been isolated and characterized [Niraj et al., 2019]. With the exception of the X chromosomal FANCB gene and an autosomal dominant variant in FANCR, biallelic mutations in any of these genes cause FA, and heterozygous variants in FANCD1 (BRCA2), FANCS (BRCA1), and FANCN (PALB2) result in elevated susceptibility to breast and ovarian cancer [Niraj et al., 2019]. In addition, the FANCN (PALB2; Partner and Localizer of Breast Cancer 2 [BRCA2]) gene appears to be mutated in gastric, pancreatic, and in head and neck cancer, mainly oral squamous cell carcinoma [Nepomuceno et al., 2017, Lott and Carvajal-Carmona, 2018;
Amenábar et al., 2019]. Moreover, several FANC genes were previously identified in a different context (e.g., FANCG as XRCC9; FANCJ as BRIP1; FANCN as PALB2; FANCO as RAD51C; FANCP as SLX4; FANCQ as ERCC4/ $X P F ; F A N C R$ as RAD51; FANCT as UBE2T; FANCU as $X R C C 2$; FANCV as REV7/MAD2L2, and FANCW as RFWD3) [Knies et al., 2017]. This indicates that at the molecular genetic level, FA is related to disorders of DNA damage response. Finally, the phenotypes of FA show a great deal of functional overlap with Roberts (due to biallelic mutations in the acetyltransferase encoding ESCO2 gene) and Warsaw Breakage syndromes (due to biallelic mutations in the DNA helicase encoding DDX11/ChlR1 gene) [van der Lelij et al., 2010]. Several patients presenting with vertebral anomalies, anal atresia, cardiac abnormalities, tracheoesophageal fistula, renal anomalies, and a radial limb (VACTERL), and also including hydrocephalus (VACTERL-H) were initially diagnosed as cases of VACTERL association with hydrocephalus and BallerGerold syndrome [Rossbach et al., 1996]. This diagnosis was rescinded and changed to FA after the patients developed bone marrow failure. FA patients also show phenotypic overlap with Seckel syndrome, Nijmegen breakage syndrome, Dubowitz syndrome, Holt-Oram syndrome, thrombocytopenia absent radius syndrome, TownesBrocks syndrome, Saethre-Chotzen syndrome, velocardiofacial syndrome, Diamond-Blackfan anemia, and dyskeratosis congenita [Auerbach, 2009]. 
Although the combination of pancytopenia, skin hyperpigmentation (in particular café-au-lait spots), skeletal malformations (in particular of the radius and the thumb), small stature, and urogenital abnormalities in a child is sufficient to raise the suspicion of FA, the spectrum of clinical phenotypes of FA may also include cardiopulmonary, gastrointestinal, and eye, ear and central nervous system abnormalities [Auerbach, 2009]. Hence, a clinical suspicion of FA needs to be corroborated by laboratory tests. After an early observation of spontaneous chromosome aberrations in cells from a FA patient, the DNA interstrand crosslinking compound cisplatin, but not the DNA-protein crosslinking transplatin, was found to elicit a significantly higher number of chromosome aberrations [Schroeder et al., 1964; Poll et al., 1982]. Subsequently, karyotyping of stimulated lymphocytes after challenge with DNA interstrand crosslinking drugs such as diepoxybutane or mitomycin C was recommended as a diagnostic standard [Giampietro et al., 1993].

Both stimulated lymphocytes and fibroblasts from FA patients grow poorly in culture, despite normal recruitment and growth fraction [Kubbies et al., 1985]. This poor proliferation, and the frequently occurring endomitosis of FA was explained by a prominent arrest of cells in the G2 phase of the cell cycle [Kubbies et al., 1985]. In addition, cultured fibroblasts from FA patients showed a marked sensitivity to the ambient oxygen level in the culture vessel, which was detectable in both the karyotype and the cell cycle behavior of the cells [Joenje et al., 1981; Schindler and Hoehn, 1988]. The pattern of disturbed cell cycle behavior of FA cells is clearly distinct from that elicited by cumene hydroperoxide, a model compound for lipid peroxides, and 4-hydroxynonenal, the major breakdown product of lipid peroxides [Poot et al., 1988]. These in vitro studies indicate that FA cells suffer from a defective response to DNA interstrand crosslinks and to some sort of oxygen induced cell damage.

The thus far discovered FA genes can be divided into several categories: genes making up the FA core complex (FANCA, FANCB, FANCC, FANCF, FANCG [XRCC9], FANCL, FANCM, FANCT), those comprising the ID complex (FANCD2, FANCI, FANCP [XLC4]), those involved in homologous recombination (FANCJ [BRIP1], FANCN [PALB2], FANCO [RAD51C], FANCR [RAD51], FANCS [BRCA1], FANCU [XCCR2]), and a miscellaneous category of genes to which no function has yet been attributed [Datta and Brosh, 2019; Niraj et al., 2019]. Almost $90 \%$ of the FA patients carry mutations in one of the 9 genes making up the FA core complex, while the other 13 FANC genes are mutated in the remaining $10 \%$ of the

FA: Anemia and Skeletal Malformations Progressing to a Gene Network
FA patients [Niraj et al., 2019]. The number of FANC genes and the distribution of mutations among FA patients make a molecular genetic diagnosis challenging. In some ethnic groups (Askenazy Jews, Spanish Gypsies) relatively common founder mutations should be considered first [Gille et al., 2012]. If there are no clues for a founder mutation, FANCC, FANCE, FANCF, and FANCG should be analyzed by Sanger sequencing, and in case the patient is male, an MLPA test of the FANCB gene is recommended [Gille et al., 2012]. All in all, this is a cost-effective strategy for institutions with limited resources. If whole-exome sequencing is available, the entire complement of FANC and associated genes can be analyzed at once [Ameziane et al., 2012]. The results are first inspected for possible indels or deletions, and, if none are found, the variants are filtered against the database of single-nucleotide polymorphisms (dbSNP). The remaining variants are then evaluated for their possible pathogenic effect using several of the bioinformatic tools available online. If no probably pathogenic variants are found, the introns and the untranslated regions of the FANC genes should be sequenced [Ameziane et al., 2012].

With the pathogenic variants at hand one can determine their phenotypic effects, which is crucial for the clinical management of FA patients, genetic counseling of their families, and uncovering of genotype-phenotype correlations and their prognostic implications. To do so, one needs to consider the role of the FANC genes in processes such as interstrand crosslink repair, double-strand break repair, mismatch repair, and nucleotide excision repair [Datta and Brosh, 2019]. The WRN-encoded helicase/exonuclease is also involved in interstrand crosslink repair and double-strand break repair, but the clinical phenotypes of FA and Werner syndrome are clearly distinct [Poot et al., 2001; 2004]. Yet, it is conceivable that WRN might serve as a backup to the FA pathway [Datta and Brosh, 2019]. FANCA, FANCB, FANCC, FANCD1 (BRCA2), FANCD2, FANCE, FANCF, FANCG, FANCL, and FANCM, being involved in interstrand crosslink repair, received particular attention [Levitus et al., 2006]. Overall, variants in FANCB, FANCD2, and in the genes of the ID complex; i.e., FANCD2, FANCI, FANCP (XLC4), which are involved in homologous recombination, were associated with specific anomalies such as renal malformations, microcephaly, short stature, and the combination of VACTERL-H phenotypes [Fiesco Roa et al., 2019]. In individuals with FANCD2 variants, making up 3-6\% of all FA patients, skeletal abnormalities were frequently observed [Kalb et al., 2007]. In addition, the hematological manifestations of FA appear earlier and progress more 
rapidly in comparison to all other patients. Of the $66 \mathrm{mu}$ tated FANCD2 alleles in this cohort, 34 resulted in aberrant splicing patterns [Kalb et al., 2007]. Many mutations prove recurrent and exhibit ethnic associations and shared allelic haplotypes. Interestingly, there were no biallelic null mutations, such that in all available patient cell lines residual FANCD2 protein of both isotypes was detected.

In another multi-ethnic study, most of the $111 \mathrm{FA}$ patients had confirmed mutations in FANCA (67\%), FANCC (13\%), FANCG (14\%), FANCD1 (2\%), and FANCJ (3\%) [Steinberg-Shemer et al., 2020]. Patients with FANCA mutations developed hematological malignancies and cancer more often and at an older age than patients with mutations in the other FANC genes. Nevertheless, the overall survival of the patients did not depend on the affected gene. A study of 216 FA families enrolled in the International Fanconi Anemia Registry turned up 57 large deletions and 261 FANCA sequence variants in 159 families [Kimble et al., 2018]. This study again highlights the preponderance of FANCA variants and shows that roughly one-third of them were due to large deletions. By RNA analysis, two variants (c.522G $>C$ and c. $1565 \mathrm{~A}>\mathrm{G}$ ) were predicted to encode missense mutations causing skipping of exons 5 and 16, respectively. They proved to be nonpathogenic by the mitomycin $\mathrm{C}$ sensitivity assay. They are therefore classified as likely pathogenic [Kimble et al., 2018]. While proteins resulting from pathogenic missense variants were found to reside in the cytoplasm, non-pathogenic ones were located in the nucleus.

In 11 FA patients homozygous or compound heterozygous for the p.His913Pro and the p.Arg951Gln/Trp variant of FANCA, the encoded proteins were stably expressed in the cytoplasm [Bottega et al., 2018]. Thus, they are not able to migrate into the nucleus and to repair DNA lesions. In these cases, the electron transfer between respiration complex I-III is reduced, and the ATP/AMP ratio is decreased. Both pyruvate + malate and succinate supported respiration, which indicates that respiration complexes I (coenzyme Q reductase) and II (succinate dehydrogenase) were not affected by these FANCA variants. There was no evidence for uncoupling of oxygen consumption and ATP production. The precise biochemical mechanism(s) of how these FANCA variants affect mitochondrial respiration remain(s) to be elucidated as well as to what extent this mitochondrial phenotype relates to the oxygen sensitivity of FA cells [Joenje et al., 1981; Schindler and Hoehn, 1988].

A study of 113 Japanese FA patients identified $215 \mathrm{mu}-$ tant alleles of which 130 were in the FANCA gene [Mori et al. 2019]. They were discovered in $68 \mathrm{FA}$ patients from
59 unrelated families, and consisted of 55 different FAN$C A$ variants. They included 9 missense mutations, 8 nonsense mutations, 16 small insertions/deletions (indels), 12 large deletions, one large duplication, and 9 splicing mutations. The mutational spectrum in Japanese patients was broad, as that in previous studies, but some variants were recurrent. The FANCA c.2546delC variant occurred in 41 out of 130 alleles (31.5\%). The FANCA c.2546delC variant was found at a frequency of $0.08 \%$ among 3,554 healthy individuals from 3.5KJPNv2 in the ToMMo database, but not in the ExAC database. This variant was also common among Korean FA patients, and thus seems to be a hotspot in the East Asian populations. Considering the allele frequencies of FA-associated deleterious variants in 3,554 healthy individuals, the authors estimated that approximately $2.6 \%$ of the Japanese population may be carriers of pathogenic variations in FA genes. In line with this, the Japanese Society of Pediatric Hematology/Oncology reported that each year, approximately 10 individuals with FA are born per 1 million births in Japan [Yabe and Yabe, 2015].

In this issue of Molecular Syndromology, Toksoy and colleagues present a clinical and molecular characterization of 20 FA patients in Turkey [Toksoy et al., 2020]. In this cohort, 15 patients and one of the parental samples carried 17 different variants in FANCA, of which 7 were novel. The remaining 5 patients had a variant in each of the FANCC, FANCD1 (BRCA2), FANCE, FANCJ (BRIP1), FANCL, and FANCN genes.

A single patient carried a novel heterozygous deletion of exon 5-6 of FANCN (PALB2) inherited from the father and a de novo nonsense variant (c.9739C>T, p.Q3247*) in exon 27 of FANCD1 (BRCA2) [Toksoy et al., 2020]. A chromosomal rearrangement was ruled out by karyotyping and microarray analysis, and deletions of FANCD1 (BRCA2) were excluded by MLPA analysis. Gonadal mosaicism could not be excluded, however. By whole-exome sequencing, additional sequence variants other than those in FANCD1 were also excluded. Yet, other pathogenic sequence variants, or gross inactivating alterations of the FANCN (PALB2) gene on the maternal allele leading to biallelic functional aberrations, are likely diseasecausing situations. Nevertheless, a digenic constellation should also be considered. The proteins encoded by FANCD1 (BRCA2) and FANCN (PALB2) interact in a complex that is involved in homologous recombination [Niraj et al., 2019]. Conceivably, these variants may weaken this interaction, and thus the functioning of the protein complex becomes impaired. Further biochemical studies are needed to resolve this. 
Another remarkable finding of this study are 2 patients with pathogenic variants in the FANCA gene $(c .3163 \mathrm{C}=$ $13163 \mathrm{C}>\mathrm{T}$, c. $2557 \mathrm{C}=12557 \mathrm{C}>\mathrm{T}$ ) in the mosaic state [Toksoy et al., 2020]. The variants were inherited from the parents, who carried these alleles in the non-mosaic heterozygous state. In DNA from a skin biopsy of one of the patients, the pathogenic allele was also in the nonmosaic state. The pathogenic variant may have been lost in a fraction of the body cells because of a postzygotic intragenic recombination event between the pathogenic and the wild type allele, as has been demonstrated in cases with FANCC variants [Lo ten Foe et al., 1997; Gross et al., 2002]. Alternative mechanisms include back mutation or gene conversion, which have been shown in FANCA patients [Gross et al., 2002]. In 3 other patients with FAN$C A$ variants secondary to compensatory sequence variation alterations in cis have been described, which constitutes a third possible mechanism of somatic mosaicism in
FA [Waisfisz et al., 1999]. Loss of an inherited pathogenic allele of the FANCA gene as observed in peripheral blood T cells, bone marrow colony-forming units, granulocyte-macrophages, and burst-forming erythroid cells underscores the clinical importance of this phenomenon in FA [Gregory et al., 2001]. It is estimated that mosaicism for pathogenic alleles occurs in some $25 \%$ of the FA patients [Lo ten Foe et al., 1997]. In view of its clinical relevance, somatic mosaicism deserves due attention, in particular detailed assessments of the hematological phenotypes and a long-term follow up of the clinical course of the patients.

This study, and those described above, indicate that the clinical and molecular spectrum of FA is far from exhausted, and novel variants and clinical phenotypes are still likely to be discovered by analyses of cohorts of FA patients like the one by Toksoy and colleagues.

Martin Poot

\section{References}

Amenábar JM, Torres-Pereira CC, Tang KD, Punyadeera $\mathrm{C}$. Two enemies, one fight: an update of oral cancer in patients with Fanconi anemia. Cancer. 2019 Nov;125(22):3936-46. ered by analyses of cohorts of FA patients as the one by Toksoy and colleagues.

Ameziane N, Sie D, Dentro S, Ariyurek Y, Kerkhoven L, Joenje $\mathrm{H}$, et al. Diagnosis of fanconi anemia: mutation analysis by next-generation sequencing. Anemia. 2012;2012:132856.

Auerbach AD. Fanconi anemia and its diagnosis. Mutat Res. 2009 Jul;668(1-2):4-10.

Bottega R, Nicchia E, Cappelli E, Ravera S, De Rocco D, Faleschini M, et al. Hypomorphic FANCA mutations correlate with mild mitochondrial and clinical phenotype in Fanconi anemia. Haematologica. 2018 Mar; 103(3): $417-26$.

Datta A, Brosh RM Jr. Holding All the CardsHow Fanconi Anemia Proteins Deal with Replication Stress and Preserve Genomic Stability. Genes (Basel). 2019 Feb;10(2):170-94.

de Winter JP, Léveillé F, van Berkel CG, Rooimans MA, van Der Weel L, Steltenpool J, et al. Isolation of a cDNA representing the Fanconi anemia complementation group E gene. Am J Hum Genet. 2000b Nov;67(5):1306-8.

de Winter JP, Rooimans MA, van Der Weel L, van Berkel CG, Alon N, Bosnoyan-Collins L, et al. The Fanconi anaemia gene FANCF encodes a novel protein with homology to ROM. Nat Genet. 2000a Jan;24(1):15-6.

de Winter JP, Waisfisz Q, Rooimans MA, van Berkel CG, Bosnoyan-Collins L, Alon N, et al. The Fanconi anaemia group G gene FANCG is identical with XRCC9. Nat Genet. 1998 Nov;20(3):281-3.
Fanconi G. Familiaere infantile perniziösartige Anaemie (pernizioeses Blutbild und Konstitution). Jahrb Kinderheilk. 1927;117:257-80.

Fiesco-Roa MO, Giri N, McReynolds LJ, Best AF, Alter BP. Genotype-phenotype associations in Fanconi anemia: A literature review. Blood Rev. 2019 Sep;37:100589.

Giampietro PF, Adler-Brecher B, Verlander PC, Pavlakis SG, Davis JG, Auerbach AD. The need for more accurate and timely diagnosis in Fanconi anemia: a report from the International Fanconi Anemia Registry. Pediatrics. 1993 Jun;91(6):1116-20.

Gille JJP, Floor K, Kerkhoven L, Ameziane N, Joenje H, deWinter JP: Diagnosis of Fanconi Anemia: Mutation Analysis by Multiplex Ligation-Dependent Probe Amplification and PCR-Based Sanger Sequencing. Anemia. 2012;2012:603253

Gregory Jr. JJ, Wagner JE, Verlander PC, Levran O, Batish SD et al.: Somatic mosaicism in Fanconi anemia: evidence of genotypic reversion in lymphohematopoietic stem cells. Proc Natl Acad Sci USA. 2001;98:2532-7.

Gross M, Hanenberg H, Lobitz S, Friedl R, Herterich S, Dietrich R, et al. Reverse mosaicism in Fanconi anemia: natural gene therapy via molecular self-correction. Cytogenet Genome Res. 2002;98(2-3):126-35.

Joenje H, Arwert F, Eriksson AW, de Koning H, Oostra AB. Oxygen-dependence of chromosomal aberrations in Fanconi's anaemia. Nature. 1981 Mar;290(5802):142-3.
Kalb R, Neveling K, Hoehn H, Schneider H, Linka Y, Batish SD, et al.: Hypomorphic Mutations in the Gene Encoding a Key Fanconi Anemia Protein, FANCD2, Sustain a Significant Group of FA-D2 Patients with Severe Phenotype. Am J Hum Genet. 2007 May;80(5):895910.

Kimble DC, Lach FP, Gregg SQ, Donovan FX, Flynn EK, Kamat A, et al. A comprehensive approach to identification of pathogenic FANCA variants in Fanconi anemia patients and their families. Hum Mutat. 2018 Feb; 39(2):237-54.

Knies K, Inano S, Ramírez MJ, Ishiai M, Surrallés $\mathrm{J}$, Takata $\mathrm{M}$, et al. Biallelic mutations in the ubiquitin ligase RFWD3 cause Fanconi anemia. J Clin Invest. 2017 Aug;127(8):3013-27.

Kubbies M, Schindler D, Hoehn H, Schinzel A, Rabinovitch PS: Endogenous blockage and delay of the chromosome cycle despite normal recruitment and growth phase explain poor proliferation and frequent endomitosis in Fanconi anemia cells. Am J Hum Genet. 1985 Sep;37(5):1022-30.

Levitus M, Joenje H, de Winter JP. The Fanconi anemia pathway of genomic maintenance. Cell Oncol. 2006;28(1-2):3-29.

Lo Ten Foe JR, Kwee ML, Rooimans MA, Oostra $A B$, Veerman AJ, van Weel M, et al. Somatic mosaicism in Fanconi anemia: molecular basis and clinical significance. Eur J Hum Genet. 1997 May-Jun;5(3):137-48.

Lo Ten Foe JR, Rooimans MA, Bosnoyan-Collins L, Alon N, Wijker M, Parker L, et al. Expression cloning of a cDNA for the major Fanconi anaemia gene, FAA. Nat Genet. 1996 Nov; 14(3):320-3.
FA: Anemia and Skeletal Malformations Progressing to a Gene Network
Mol Syndromol 2020;11:178-182 DOI: $10.1159 / 000510878$ 
Lott PC, Carvajal-Carmona LG. Resolving gastric cancer aetiology: an update in genetic predisposition. Lancet Gastroenterol Hepatol. 2018 Dec;3(12):874-83.

Mori M, Hira A, Yoshida K, Muramatsu H, Okuno Y, Shiraishi Y, et al. Pathogenic mutations identified by a multimodality approach in 117 Japanese Fanconi anemia patients. Haematologica. 2019 Oct;104(10):1962-73.

Nepomuceno TC, De Gregoriis G, de Oliveira FM, Suarez-Kurtz G, Monteiro AN, Carvalho MA. The Role of PALB2 in the DNA Damage Response and Cancer Predisposition. Int J Mol Sci. 2017 Aug;18(9):1886.

Niraj J, Färkkilä A, D'Andrea AD. The Fanconi Anemia Pathway in Cancer. Annu Rev Cancer Biol. 2019 Mar;3(1):457-78.

Poll EH, Arwert F, Joenje H, Eriksson AW. Cytogenetic toxicity of antitumor platinum compounds in Fanconi's anemia. Hum Genet. 1982;61(3):228-30.

Poot M, Esterbauer H, Rabinovitch PS, Hoehn H. Disturbance of cell proliferation by two model compounds of lipid peroxidation contradicts causative role in proliferative senescence. J Cell Physiol. 1988 Dec;137(3):421-9.
Poot M, Jin X, Hill JP, Gollahon KA, Rabinovitch PS. Distinct functions for WRN and TP53 in a shared pathway of cellular response to 1-beta-D-arabinofuranosylcytosine and bleomycin. Exp Cell Res. 2004 Jun;296(2):327-36.

Poot M, Yom JS, Whang SH, Kato JT, Gollahon KA, Rabinovitch PS. Werner syndrome cells are sensitive to DNA cross-linking drugs. FASEB J. 2001 May;15(7):1224-6.

Rossbach HC, Sutcliffe MJ, Haag MM, Grana NH, Rossi AR, Barbosa JL. Fanconi anemia in brothers initially diagnosed with VACTERL association with hydrocephalus, and subsequently with Baller-Gerold syndrome. Am J Med Genet. 1996 Jan;61(1):65-7.

Schindler D, Hoehn H. Fanconi anemia mutation causes cellular susceptibility to ambient oxygen. Am J Hum Genet. 1988 Nov;43(4):42935.

Schroeder TM, Anschütz F, Knopp A. [Spontaneous chromosome aberrations in familial panmyelopathy]. Humangenetik. 1964;1(2):194-
Steinberg-Shemer O, Goldberg TA, Yacobovich J, Levin C, Koren A, Revel-Vilk S, et al. Characterization and genotype-phenotype correlation of patients with Fanconi anemia in a multi-ethnic population. Haematologica. 2020 Jul;105(7):1825-34.

Strathdee CA, Gavish H, Shannon WR, Buchwald M. Cloning of cDNAs for Fanconi's anaemia by functional complementation. Nature. 1992 Apr;356(6372):763-7.

Toksoy G. Clinical and Molecular Characterization of Fanconi Anemia Patients in Turkey. Mol Syndromol. DOI: 10.1159/000509838.

van der Lelij P, Oostra AB, Rooimans MA, Joenje $\mathrm{H}$, de Winter JP. Diagnostic Overlap between Fanconi Anemia and the Cohesinopathies: Roberts Syndrome and Warsaw Breakage Syndrome. Anemia. 2010;2010:565268.

Waisfisz Q, Morgan NV, Savino M, de Winter JP, van Berkel CG, Hoatlin ME, et al. Spontaneous functional correction of homozygous fanconi anaemia alleles reveals novel mechanistic basis for reverse mosaicism. Nat Genet. 1999 Aug;22(4):379-83.

Yabe M, Yabe H. [Diagnosis and management of inherited bone marrow failure syndrome]. Rinsho Ketsueki. 2015 Oct;56(10):1914-21. 